Article

\title{
Salvia miltiorrhiza Induces Tonic Contraction of the Lower Esophageal Sphincter in Rats via Activation of Extracellular $\mathrm{Ca}^{2+}$ Influx
}

\section{Ching-Chung Tsai ${ }^{1,2}$, Li-Ching Chang ${ }^{3,4, *, \dagger}$, Shih-Che Huang ${ }^{5,6}$, Shu-Leei Tey ${ }^{2}$, Wen-Li Hsu ${ }^{7}$, Yu-Tsun Su ${ }^{2}$, Ching-Wen Liu ${ }^{1}$ and Tong-Rong Tsai ${ }^{1, *, \dagger}$}

1 School of Pharmacy, Kaohsiung Medical University, No.100, Shih-Chuan 1st Road, Sanmin District, Kaohsiung City 807, Taiwan; E-Mails: u101130@yahoo.com.tw (C.-C.T.) ; fruit0227@hotmail.com (C.-W.L.)

2 Departments of Pediatrics, E-Da Hospital, I-Shou University, No.1, Yida Road, Jiaosu Village, Yanchao District, Kaohsiung City 824, Taiwan; E-Mails: djsr2000@hotmail.com (S.-L.T.); suyutsun@yahoo.com.tw (Y.-T.S.)

3 Department of Occupational Therapy, I-Shou University, No.8, Yida Road, Jiaosu Village, Yanchao District, Kaohsiung City 824, Taiwan

4 Department of Pharmacy, E-Da Hospital, I-Shou University, No.1, Yida Road, Jiaosu Village, Yanchao District, Kaohsiung City 824, Taiwan

5 Department of Internal Medicine, E-Da Hospital, I-Shou University, No.1, Yida Road, Jiaosu Village, Yanchao District, Kaohsiung City 824, Taiwan; E-Mail: shihchehuang@hotmail.com

6 School of Medicine, I-Shou University, No. 8, Yida Road, Jiaosu Village, Yanchao District, Kaohsiung City, 824, Taiwan

7 Institute of Basic Medical Sciences, Medical College, National Cheng Kung University, No.1, Dasyue Road, East District, Tainan City 701, Taiwan; E-Mail: hsuwenli0626@gmail.com

$\dagger$ These authors contributed equally to this work.

* Authors to whom correspondence should be addressed; E-Mails: changlc@isu.edu.tw (L.-C.C.); trtsai@kmu.edu.tw (T.-R.T.); Tel.: +886-919-194-556 (L.-C.C.); +886-910-761-339 (T.-R.T.); Fax: +886-7-615-5150 (L.-C.C.); +886-7-321-0683 (T.-R.T.).

Academic Editor: Isabel C. F. R. Ferreira

Received: 18 June 2015 / Accepted: 4 August 2015 / Published: 11 August 2015

Abstract: Up to 40\% of patients with gastroesophageal reflux disease (GERD) suffer from proton pump inhibitor refractory GERD but clinically the medications to strengthen the 
lower esophageal sphincter (LES) to avoid irritating reflux are few in number. This study aimed to examine whether Salvia miltiorrhiza (SM) extracts induce tonic contraction of rat LES ex vivo and elucidate the underlying mechanisms. To investigate the mechanism underlying the SM extract-induced contractile effects, rats were pretreated with atropine (a muscarinic receptor antagonist), tetrodotoxin (a sodium channel blocker), nifedipine (a calcium channel blocker), and $\mathrm{Ca}^{2+}$-free Krebs-Henseleit solution with ethylene glycol tetraacetic acid (EGTA), followed by administration of cumulative dosages of SM extracts. SM extracts induced dose-related tonic contraction of the LES, which was unaffected by tetrodotoxin, atropine, or nifedipine. However, the SM extract-induced LES contraction was significantly inhibited by $\mathrm{Ca}^{2+}$-free Krebs-Henseleit solution with EGTA. Next, SM extracts significantly induce extracellular $\mathrm{Ca}^{2+}$ entry into primary LES cells in addition to intracellular $\mathrm{Ca}^{2+}$ release and in a dose-response manner. Confocal fluorescence microscopy showed that the SM extracts consistently induced significant extracellular $\mathrm{Ca}^{2+}$ influx into primary LES cells in a time-dependent manner. In conclusion, SM extracts could induce tonic contraction of LES mainly through the extracellular $\mathrm{Ca}^{2+}$ influx pathway.

Keywords: Salvia miltiorrhiza; tonic contraction; lower esophageal sphincter

\section{Introduction}

Gastroesophageal reflux disease (GERD) is caused by reflux of acid or other irritants from the stomach into the esophagus. The main cause of GERD is incompetence of the lower esophageal sphincter (LES) which normally closes at the esophagogastric junction to avoid the back-up of food and acid injury and transiently relaxes to allow food from the esophagus into the stomach when swallowing [1]. Acid reflux-induced mucosal inflammation may affect muscle and nerves, and then affect LES and esophageal body motility. Further acid reflux and mucosal damage may cause a vicious cycle of impaired LES function and esophageal injury. Treatment for GERD includes lifestyle modifications, medications, and surgery. Proton-pump inhibitors (PPI), histamine type II receptor blockers or antacids are common medications for GERD. PPI is the first-line medication for GERD, but $10 \%-40 \%$ patients with GERD are refractory to PPI and furthermore, long term use of PPI may lead to complications [2]. The surgery for severe GERD usually involves strengthening the LES and repairing the hiatus hernia [3]. Clinically, there are few medications, such as baclofen which decreases LES relax and then indirectly increases LES pressure for the patients with PPI refectory GERD. However, baclofen may cause central nervous system side effects [4]. Therefore, treatment of PPI refractory GERD is still a challenge and it is important to develop drugs that increase LES contraction to avoid irritant reflux.

Salvia miltiorrhiza Bunge (SM), also known as red sage or Danshen in Chinese, is clinically used in Traditional Chinese Medicines and officially listed by the Pharmacopoeia Commission of the People's Republic of China [5]. SM is a common drug affecting blood viscosity and its effects include improving blood circulation, removing blood stasis, promoting blood flow in menstruation, resolving mental uneasiness and restlessness, nourishing the blood, tranquilizing the mind, eliminating and breaking stone, treating gurgling in the intestines, relieving fullness, and resolving swelling [6,7]. SM or its active 
components are widely used as an alternative medicine to treat coronary heart disease, cerebrovascular disease, hepatitis, cirrhosis, chronic renal failure and osteoporosis, and SM has been reported to have anti-cancer effects [8-12].

There are a few studies of SM concerning gastrointestinal motility or disorders to date. The increase in expression of cholecystokinin and vasoactive intestinal peptide in the jejunum was suppressed by SM pretreatment, which might contribute to the early recovery of gastrointestinal motility in digestive tract congestion injury caused by liver ischemia [13]. SM can decrease the inflammation of colon induced by dextran sulfate sodium in rats [14]. SM can ameliorate the pathological changes in the small intestine, spleen and thymus and decrease the mortality rate of rats suffering from severe acute pancreatitis [15]. Our previous study found that $\mathrm{SM}$ can induce tonic contraction of the ileal tube in rats through intracellular $\mathrm{Ca}^{2+}$ release and the $\mathrm{Ca}^{2+}$-calmodulin pathway [16].

To the best of our knowledge, no study about the effects of SM on LES has been reported to date. The aim of this study is to therefore to investigate the contractile effects of SM extracts on LES and the mechanism(s) involved. We found that SM extracts can induce LES contractile responses ex vivo. To explore the mechanisms that mediate SM extracts-induced contraction of LES, atropine (a muscarinic receptor antagonist), tetrodotoxin (a neuronal sodium channel blocker), nifedipine (a calcium channel blocker), or $\mathrm{Ca}^{2+}$-free Krebs-Henseleit solution with ethylene glycol tetraacetic acid (EGTA) was given and then cumulative dosages of SM were added. Then, the isometric contractions of LES muscle strips were measured in organ baths.

\section{Results and Discussion}

\subsection{The Content of Tanshinone IIA (TA) in SM Extracts}

According to the Pharmacopoeia Commission of the People's Republic of China [5], TA has been used mainly for quality control of the roots of S. miltiorrhiza Bunge (Danshen). The content of TA was detected by high performance liquid chromatography (HPLC) and quantified as $1190 \mu \mathrm{g} / \mathrm{mL}$ in SM extracts. The extraction yield of TA from SM roots was calculated as $0.0595 \%$.

\subsection{Dose-Response Effect of SM Extracts on Contraction of LES}

SM extracts produced a dose-dependent tonic contraction on isolated LES of rat. Figure 1A shows typical tracings of SM extract-induced tonic contraction of rat LES. Figure 1B shows the contractile responses and area under the contraction curve (AUC) produced in rat LES by the application of increasing concentrations of SM. Compared to the basal line, the AUC on the contraction curves on cumulative dose of $40,100,180$, and $280 \mu \mathrm{L}$ SM extracts were $324.8 \pm 6.5,537.8 \pm 23.8,956.3 \pm 158.4$, and $1927.4 \pm 361.7$ (g/g of tissue weight/s) respectively. Thus, SM enhanced the contractile activity of LES in a dose-response manner. The LES contraction curves induced by cumulative doses of 40 and $100 \mu \mathrm{L}$ SM extracts returned to prestimulation levels after removing SM extracts with Krebs-Henseleit solution (Figure 1C). Therefore, the tonic contraction of LES induced by SM extracts was reversible. After removing SM extracts with normal Krebs-Henseleit solution, the LES maximum contraction was remeasured by carbachol addition. The contractile percentage of LES after SM treatment was 
$96.3 \% \pm 1.1 \%$ of pre-SM stimulation level $(p>0.05)$. Thus, the increased tonic contraction of LES induced by SM extracts probably does not happen via toxic effects.

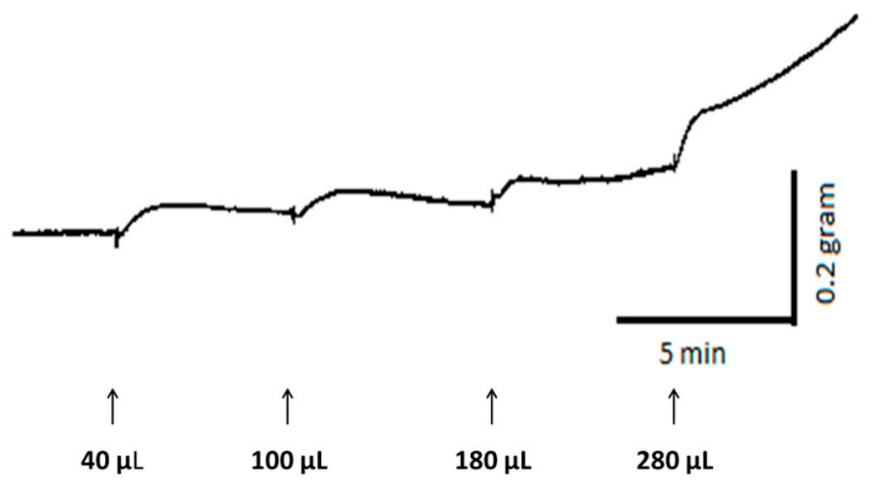

(A)

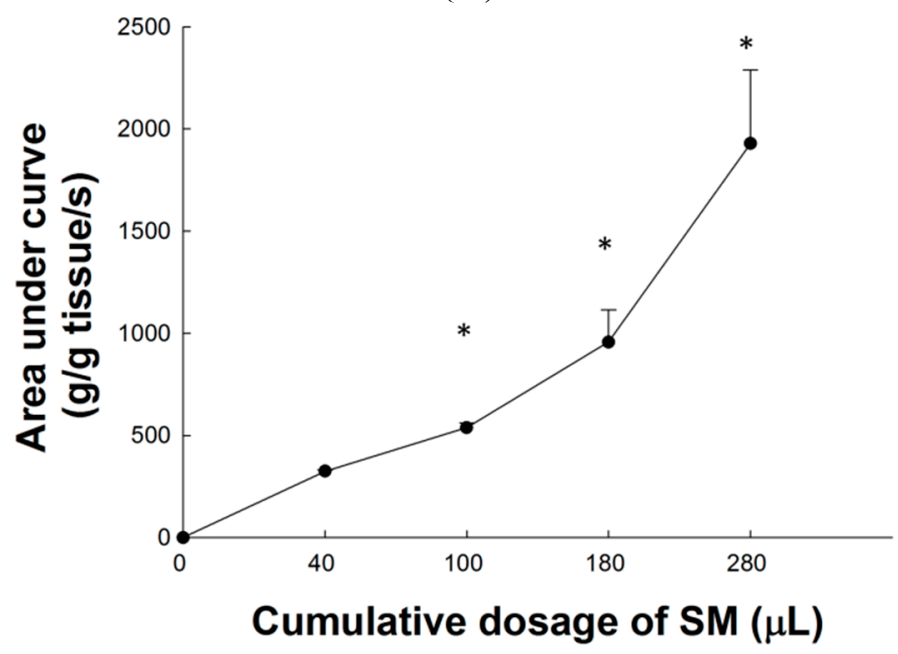

(B)
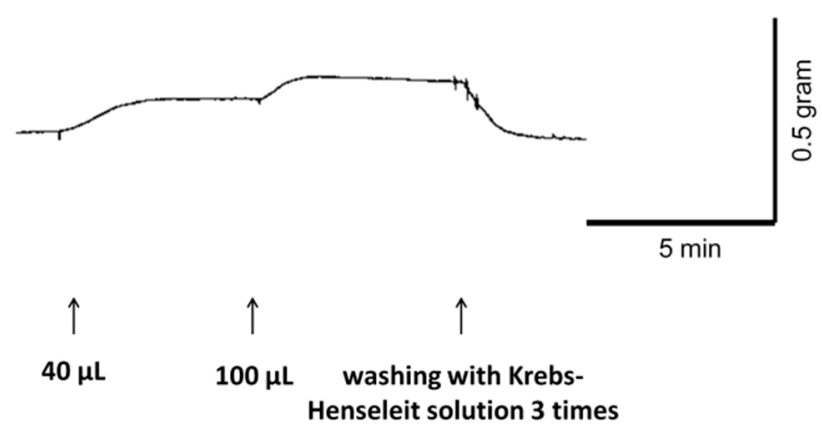

(C)

Figure 1. The SM extracts-induced contractions of LES in rat. (A) Typical tracing of the contraction of LES in rat in response to cumulative addition of SM extracts; (B) Concentration-response curves for the SM extracts-induced contractions of rat LES. Arrows indicate the addition of SM extracts on cumulative dosage at intervals of $5 \mathrm{~min}$; (C) Contraction curve of LES returned to prestimulation level after removing SM extracts with Krebs-Henseleit solution. The contractile change was compared to resting contractility of corresponding experiments. * Significantly different from the resting contractility at $p<0.05$. 
The mechanism controlling the contractile activity of the LES is incompletely understood. It may be regulated or modulated by many factors, such as nerve ending-smooth muscle interactions, neurohumoral substances, diet and drugs [17]. This study identified for the first time that SM extracts can induce tonic contraction of LES in rats. The contraction of the smooth muscle of LES is affected by multiple factors but mainly by autonomic neural innervations. Excitatory postganglionic vagal nervous terminals release acetylcholine (ACh) in the myenteric plexus, resulting in activation of muscarinic $(\mathrm{M})$ receptors. Activation of $\mathrm{M}$ receptors increases the intracellular concentration of $\mathrm{Ca}^{2+}$. Increased cytosolic $\mathrm{Ca}^{2+}$ comes from the extracellular entry through trans-membrane $\mathrm{Ca}^{2+}$ channels or/and the release of intracellular $\mathrm{Ca}^{2+}$ stores [18]. An increase in cytoplasmic calcium concentration, binding to calmodulin and resulting in $\mathrm{Ca}^{2+} /$ calmodulin-dependent activation of myosin light chain kinase (MLCK), is an important pathway for contraction of LES. In addition, resting LES tone is related to a protein kinase C-dependent pathway [19]. Various mechanisms may be involved in the SM extract-induced contraction of LES and they are described as follows.

\subsection{Effect of Tetrodotoxin (TTX) on SM Extracts-Induced Contraction of LES}

TTX has no significant effect on the area under the contraction curve of SM extract-induced contraction of LES. As shown in Figure 2A, the dose-response curves of SM extracts were almost unaffected by 15 min pretreatment with TTX ( $p>0.05$ compared with administration of SM extracts, $n=3$ ). The efferent neurons from excitatory vagal nerves have the main regulatory action to increase LES tone. TTX is a selective neuronal $\mathrm{Na}^{+}$channel blocker. To investigate whether SM acts directly on the nerve fiber or on smooth muscle of LES, the effect of TTX $\left(10^{-6} \mathrm{M}\right)$ on SM-induced tonic contraction of LES was examined in the present study. No significant difference of TTX on SM extracts-induced contraction of LES was observed, compared to control. The result suggests that SM does not act directly on the nerve fibers of LES.

\subsection{Effect of Atropine on SM Extract-Induced Contraction of LES}

The non-selective muscarinic receptor antagonist atropine $\left(10^{-6} \mathrm{M}\right)$ was also studied its relation to SM extracts-induced contraction of LES. As shown in Figure 2B, 6-min pretreatment with atropine has no significant effect on SM extracts-induced contraction of LES $(p>0.05, n=3)$.

In LES, excitatory postganglionic myenteric neurons, releasing acetylcholine and its derivatives such as carbachol, activate muscarinic receptors, inducing increased cytosolic $\left[\mathrm{Ca}^{2+}\right]_{\mathrm{i}}$ and contraction [20]. Muscarinic receptors are divided into five subtypes, $\mathrm{M}_{1}-\mathrm{M}_{5}$. Among them, the $\mathrm{M}_{1}, \mathrm{M}_{2}$ and $\mathrm{M}_{3}$ receptors are thought to be the main ones associated with the contraction of LES. Non-selective muscarinic receptor antagonists like atropine can block the $\mathrm{M}_{1-5}$ receptors. To understand the mechanism underlying the contractile effects of SM extracts on LES, atropine was used to investigate the possible involvement of the cholinergic pathway. We found that atropine $\left(10^{-6} \mathrm{M}\right)$ failed to inhibit SM extract-induced contraction of LES, indicating that the SM extract-induced contraction might not be mediated through the muscarinic receptors. 


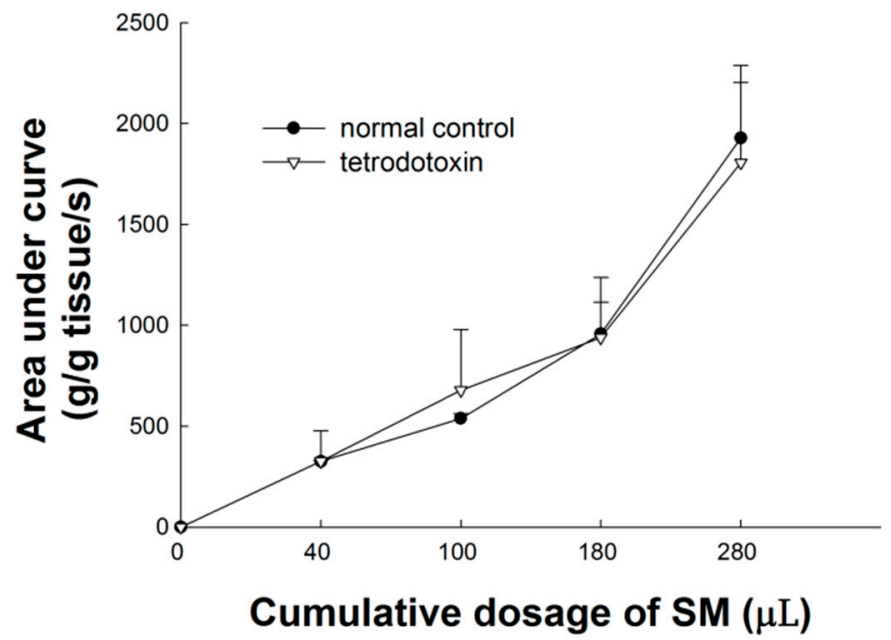

(A)

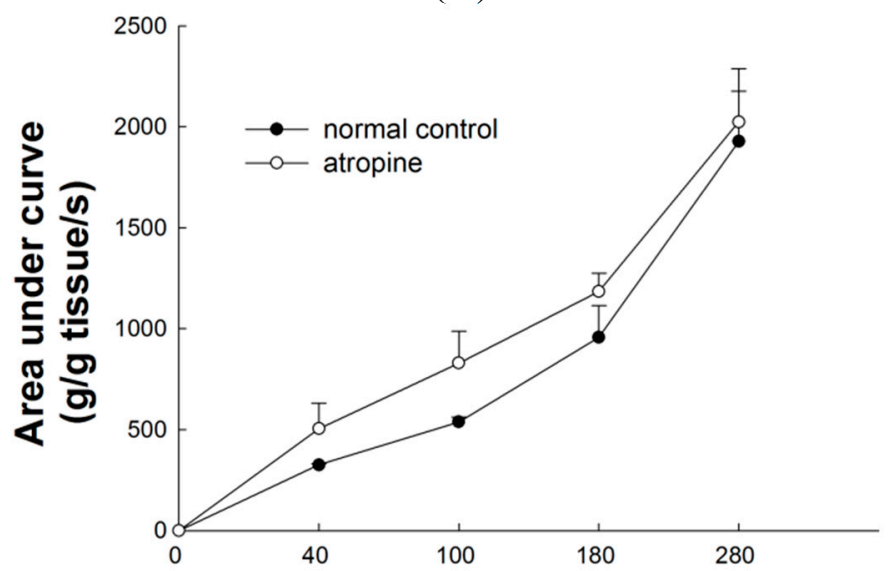

Cumulative dosage of SM $(\mu \mathrm{L})$

(B)

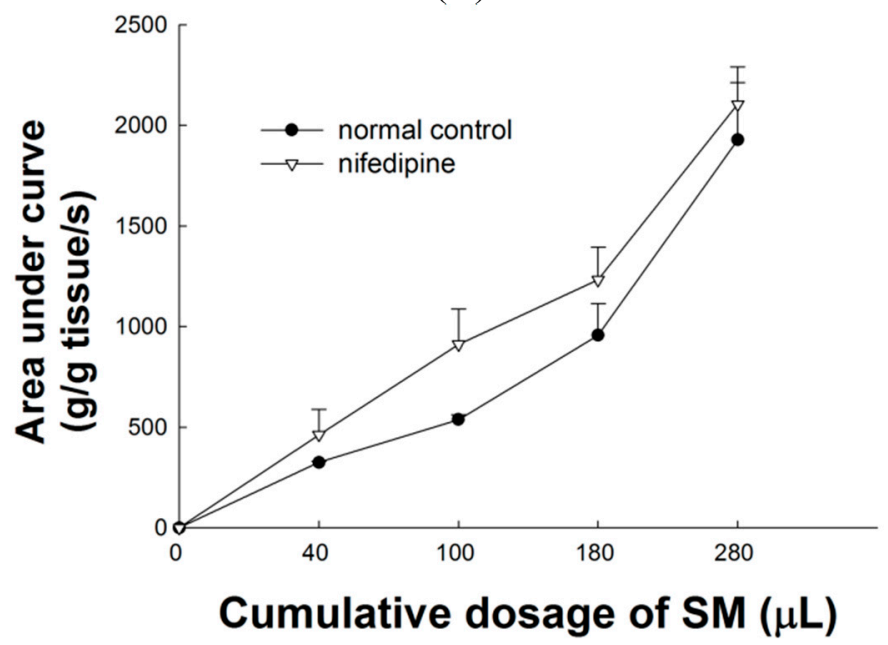

(C)

Figure 2. Effects of pretreatment with TTX, atropine and nifedipine on contraction of LES induced by SM extracts. (A) TTX $\left(10^{-6} \mathrm{M}\right)$ has no significant effect on contraction of LES induced by SM extracts; (B) Atropine $\left(10^{-6} \mathrm{M}\right)$ has no significant effect on contraction of LES induced by SM extracts; $(\mathbf{C})$ Nifedipine $\left(10^{-6} \mathrm{M}\right)$ has no significant effect on contraction of LES induced by SM extracts. 


\subsection{Effect of L-Type $\mathrm{Ca}^{2+}$ Channel Blocker on SM Extract-Induced Contraction of LES}

The L-type $\mathrm{Ca}^{2+}$ channel blocker nifedipine $\left(10^{-6} \mathrm{M}\right)$ has no significant effect on the area under the contraction curve of SM extract-induced contraction of LES. As shown in Figure $2 \mathrm{C}$, the dose-response curve of SM extracts was almost unaffected by a 20 min pretreatment with nifedipine $(p>0.05, n=3)$. We confirmed that the L-type $\mathrm{Ca}^{2+}$ channel blocker, nifedipine, failed to block SM extract-induced contraction of LES.

\subsection{Effect of $\mathrm{Ca}^{2+}$-Free Krebs-Henseleit Solution plus EGTA on SM Extract-Induced Contraction of LES}

Compared to the basal line, the AUC of the contraction curves after cumulative doses of 40, 100, 180 , and $280 \mu \mathrm{L}$ SM extracts were $140.4 \pm 45.6,260.3 \pm 22.3,383.7 \pm 33.8$, and $460 \pm 82.1(\mathrm{~g} / \mathrm{g}$ of tissue weight/s) respectively. $\mathrm{Ca}^{2+}$-free Krebs-Henseleit solution plus EGTA has a significant effect on different dosage of SM extract-induced tonic contraction $(p<0.05, n=3$; Figure 3$)$. In $\mathrm{Ca}^{2+}$-free Krebs-Henseleit solution (contained 0.5 mM EGTA), SM extract-induced contraction of LES was significantly different from the contractile response in Krebs-Henseleit solution.

Smooth muscle contraction of LES is generally related to an increase in cytosolic $\mathrm{Ca}^{2+}$ concentration which is produced by trans-membrane $\mathrm{Ca}^{2+}$ entry and/or by intracellular $\mathrm{Ca}^{2+}$ release [18]. Thus, in this ex vivo contraction study of LES in rats, these above results showed the extracellular $\mathrm{Ca}^{2+}$ influx pathway other than the L-type $\mathrm{Ca}^{2+}$ channel may be the main pathway of SM extract-induced contraction of LES. There are several possible pathways for calcium entrance other than the L-type $\mathrm{Ca}^{2+}$ channel in SM extract-induced smooth muscle contraction of LES. The results could be contributed to agonist-induced contraction as well as tone, including capacitative $\mathrm{Ca}^{2+}$ entry [21], a T-type $\mathrm{Ca}^{2+}$ channel [22] and other sarcolemmal $\mathrm{Ca}^{2+}$ channels, such as nonselective cationic channels and receptor-operated calcium channels [23].

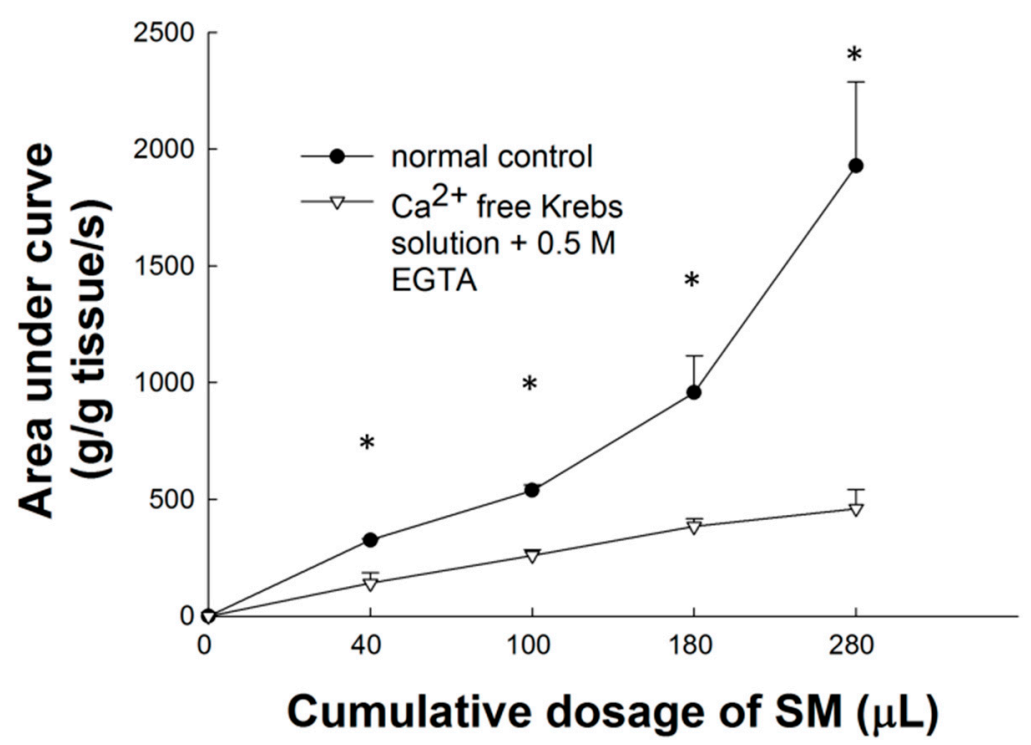

Figure 3. Effects of $\mathrm{Ca}^{2+}$-free Krebs-Henseleit solution with EGTA on contraction of induced by SM extracts. $\mathrm{Ca}^{2+}$-free Krebs-Henseleit solution with EGTA significantly $(p<0.05)$ inhibited the SM extract-induced contraction of LES in a dose-dependent manner. * Significantly different from the control at $p<0.05$. 


\subsection{Effects of SM Extracts on Cytosolic Concentration of Free $\mathrm{Ca}^{2+}\left(\left[\mathrm{Ca}^{2+}\right]_{i}\right)$ in Primary LES Smooth} Muscle Cells

The effects of SM extracts on $\left[\mathrm{Ca}^{2+}\right]_{i}$ flow from extracellular entry or intracellular release were investigated in primary LES smooth muscle cells. The mean concentration-response plots of SM-induced

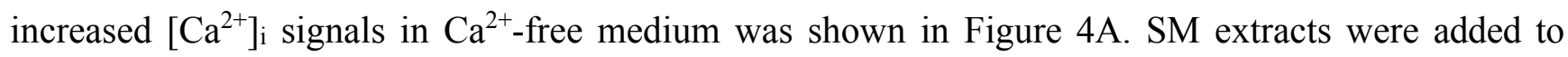
primary LES smooth muscle cells at the 60 th s (mean $\left[\mathrm{Ca}^{2+}\right] \mathrm{i}: 47.03 \pm 13.43 \mathrm{nM}$ at the 60 th $\mathrm{s}$ ). After addition of SM extracts, a short decay of $\left[\mathrm{Ca}^{2+}\right]$ i was noted and rapid rise of $\left[\mathrm{Ca}^{2+}\right]$ i followed. A sustained $\left[\mathrm{Ca}^{2+}\right]_{\mathrm{i}}$ was noted after $\left[\mathrm{Ca}^{2+}\right]_{\mathrm{i}}$ reached the top. The changes of $\left[\mathrm{Ca}^{2+}\right]_{\mathrm{i}(61-360)}$ were that mean $\left[\mathrm{Ca}^{2+}\right]_{\mathrm{i}}$ during 0-60 $\mathrm{s}$ as a background was subtracted from $\left[\mathrm{Ca}^{2+}\right]$ at each time point during $61-360 \mathrm{~s}$ As showed in Figure $4 \mathrm{~B}$, the average of $\left(\left[\mathrm{Ca}^{2+}\right]_{\mathrm{i}(61-360)}-\right.$ mean $\left.\left[\mathrm{Ca}^{2+}\right]_{\mathrm{i}(0-60)}\right)$ was calculated and the results in the groups of high $(0.5 \mu \mathrm{L} / \mathrm{mL})$ and low $(0.1 \mu \mathrm{L} / \mathrm{mL})$ concentration of SM extracts were $37.53 \pm 8.83 \mathrm{nM}$ and $18.95 \pm 7.20 \mathrm{nM}$, respectively $(p<0.05, n=3)$. This result indicated SM extracts induced intracellular $\mathrm{Ca}^{2+}$ release from intracellular stores (sarcoplasmic reticulum) in a dose-response manner.

The mean concentration-response plots of SM-induced increased $\left[\mathrm{Ca}^{2+}\right]$ i signals in $\mathrm{Ca}^{2+}$-containing medium are shown in Figure 4C. SM extract was added to primary LES smooth muscle cells at the 60th s (mean $\left[\mathrm{Ca}^{2+}\right]$ i: $99.11 \pm 4.61 \mathrm{nM}$ at the 60th s). After addition of SM extract, $\left[\mathrm{Ca}^{2+}\right] \mathrm{i}$ had a similar presentation as that in $\mathrm{Ca}^{2+}$-free medium. As shown in Figure 4D, the average of $\left(\left[\mathrm{Ca}^{2+}\right] \mathrm{i}(61-360)-\right.$ mean $\left.\left[\mathrm{Ca}^{2+}\right]_{\mathrm{i}(0-60)}\right)$ was calculated and the results in the groups of high $(0.5 \mu \mathrm{L} / \mathrm{mL})$ and low $(0.1 \mu \mathrm{L} / \mathrm{mL})$ concentration of SM extracts were $76.15 \pm 15.65 \mathrm{nM}$ and $20.91 \pm 10.26 \mathrm{nM}$, respectively $(p<0.05$, $n=3)$. Comparing Figure $4 \mathrm{D}$ with Figure $4 \mathrm{~B}$, the averages of $\left(\left[\mathrm{Ca}^{2+}\right] \mathrm{i}(61-360)-\right.$ mean $\left.\left[\mathrm{Ca}^{2+}\right] \mathrm{i}(0-60)\right)$ of these groups stimulated by high and low concentration of SM extract in the $\mathrm{Ca}^{2+}$-containing medium were significantly higher than those in the $\mathrm{Ca}^{2+}$-free medium, respectively $(76.15 \pm 15.65$ vs. $37.53 \pm 8.83 \mathrm{nM}$, $20.91 \pm 10.26$ vs. $18.95 \pm 7.20 \mathrm{nM}$, both $p<0.05$ ). Compared to low concentration SM extract, high concentrations of SM extract induce 3.64- and 1.98-fold increases $(76.15 \pm 15.65 / 20.91 \pm 10.26 \mathrm{vs}$. $37.53 \pm 8.83 / 18.95 \pm 7.20$ ) in $\mathrm{Ca}^{2+}$-containing (Figure 4D) and $\mathrm{Ca}^{2+}$-free (Figure 4B) medium, respectively $(p<0.05)$. These results indicate SM extracts induce extracellular $\mathrm{Ca}^{2+}$ entry into smooth muscle cells in addition to intracellular $\mathrm{Ca}^{2+}$ release in a dose-response manner.

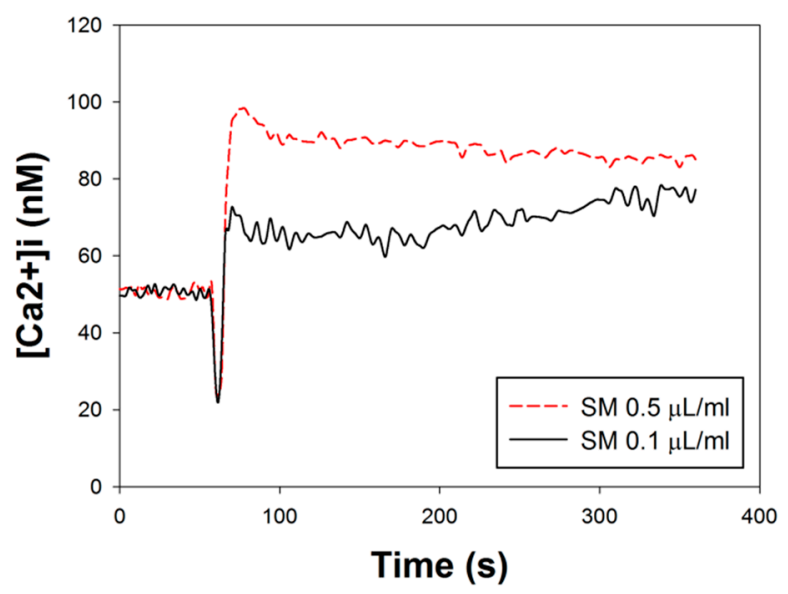

(A)

Figure 4. Cont. 


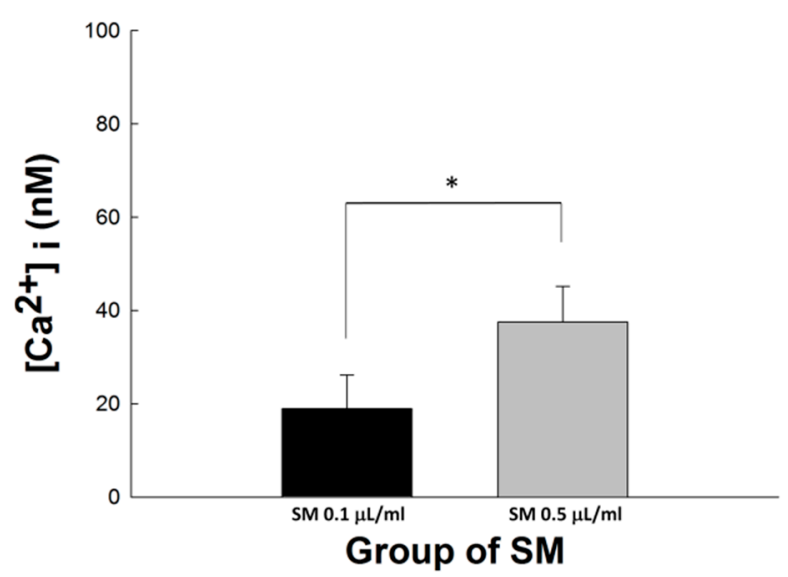

(B)

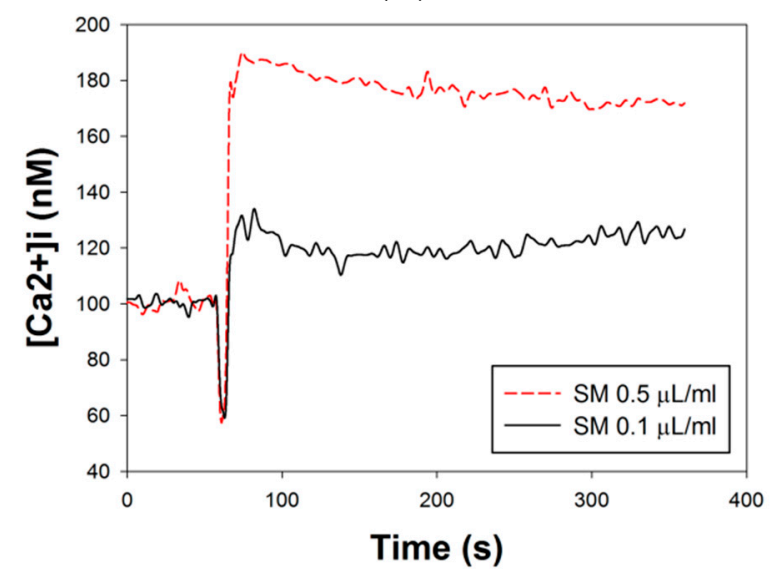

(C)

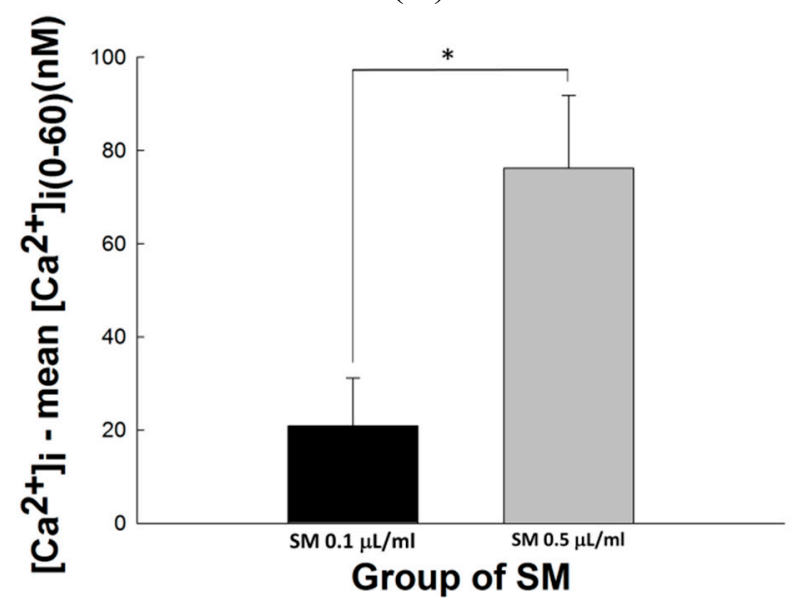

(D)

Figure 4. Effects of SM extracts on $\mathrm{Ca}^{2+}$ signaling in primary LES cells. SM extracts were diluted as $0.5 \mu \mathrm{L} / \mathrm{mL}$ or $0.1 \mu \mathrm{L} / \mathrm{mL}$ in $\mathrm{Ca}^{2+}$-containing or $\mathrm{Ca}^{2+}$-free medium. The $\mathrm{SM}$ extracts were added at the 60th $\mathrm{s}$ (A) Mean concentration-response plots of SM-induced $\mathrm{Ca}^{2+}$ signals in $\mathrm{Ca}^{2+}$-free medium; (B) The mean $\left(\left[\mathrm{Ca}^{2+}\right] \mathrm{i}(61-360)-\right.$ mean $\left.\left[\mathrm{Ca}^{2+}\right] \mathrm{i}(0-60)\right)$ in primary LES cells in $\mathrm{Ca}^{2+}$-free medium during the interval of $61-360 \mathrm{~s}$ after $\mathrm{SM}(0.5 \mu \mathrm{L} / \mathrm{mL}$ or $0.1 \mu \mathrm{L} / \mathrm{mL}$ ) treatment; (C) Mean concentration-response plots of SM-induced $\mathrm{Ca}^{2+}$ signals in $\mathrm{Ca}^{2+}$-containing medium; (D) The mean $\left(\left[\mathrm{Ca}^{2+}\right]_{\mathrm{i}(61-360)}\right.$ - mean $\left.\left[\mathrm{Ca}^{2+}\right]_{\mathrm{i}(0-60)}\right)$ in primary LES cells in $\mathrm{Ca}^{2+}$-containing medium during the interval of $61-360 \mathrm{~s}$ after $\mathrm{SM}(0.5 \mu \mathrm{L} / \mathrm{mL}$ or $0.1 \mu \mathrm{L} / \mathrm{mL}$ ) treatment. * Significantly difference between these two groups at $p<0.05$. 


\subsection{Effect of SM Extracts on Confocal Images of Changes in Intracellular $\left[\mathrm{Ca}^{2+}\right]$ in Primary LES}

Smooth Muscle Cells

Figure 5A shows the fluorescence intensity related to intracellular $\left[\mathrm{Ca}^{2+}\right]$ in primary LES cells by confocal microscopy. The three images of the upper row were detected in $\mathrm{Ca}^{2+}$-containing Buffer Salt Saline (BSS). After stimulation by SM extract at the 60th s, the fluorescence intensity of intracellular $\left[\mathrm{Ca}^{2+}\right]$ increased gradually from the 105th s (green) to the 300th s (red and bright). On the contrary, the fluorescence images of primary LES cells after SM treatment in $\mathrm{Ca}^{2+}$-free BSS showed a mild increase at the 105th s and had only a little yellow particle on central part at the 300th s Figure 5B showed the change of relative fluorescence intensity $\left(\mathrm{F}-\mathrm{F}_{0}\right.$, where $\mathrm{F}_{0}=$ the first image of the sequence and $\mathrm{F}=$ subsequent images) in the $\mathrm{Ca}^{2+}$-containing BSS. The relative fluorescence intensity (423.82 \pm 133.68$)$ of intracellular $\left[\mathrm{Ca}^{2+}\right]$ in primary LES cells at the 300th $\mathrm{s}$ was significantly higher than that at $0 \mathrm{~s}$ $(p<0.05, n=3)$. Figure $5 \mathrm{C}$ shows the change in relative fluorescence intensity $\left(\mathrm{F}-\mathrm{F}_{0}\right)$ in $\mathrm{Ca}^{2+}$-free BSS. The change of relative fluorescence intensity from $0 \mathrm{~s}$, and 105th $\mathrm{s}$ to 300th $\mathrm{s}$ was at a relatively low level. These results indicate SM extracts induce extracellular $\mathrm{Ca}^{2+}$ entry into smooth muscle cells and increase fluorescence intensity. These in vitro findings are in good agreement with our results obtained in the ex vivo study, which shows SM-induced contraction of LES is mainly associated with extracellular $\mathrm{Ca}^{2+}$ influx.
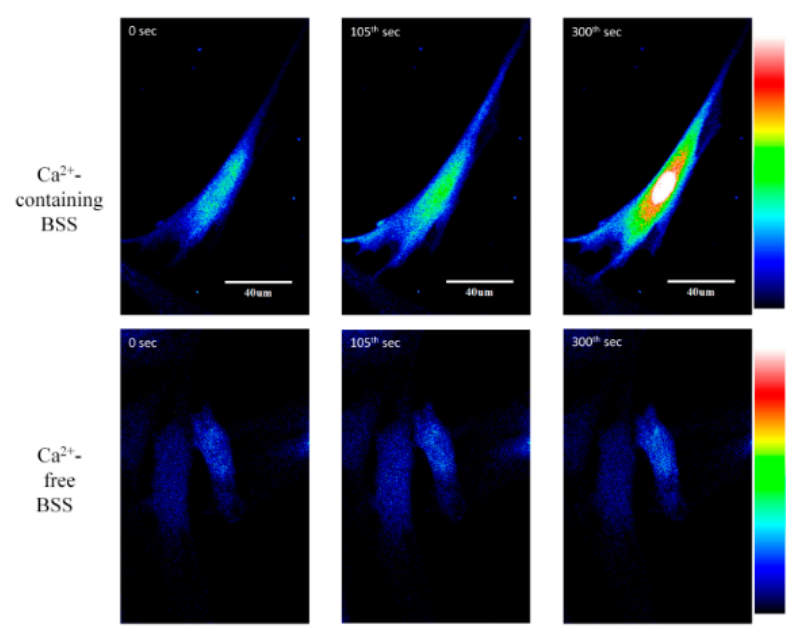

(A)

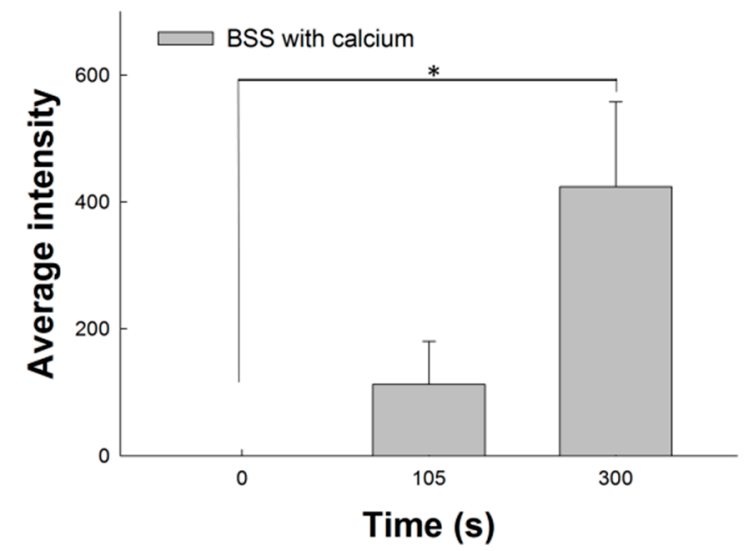

(B)

Figure 5. Cont. 


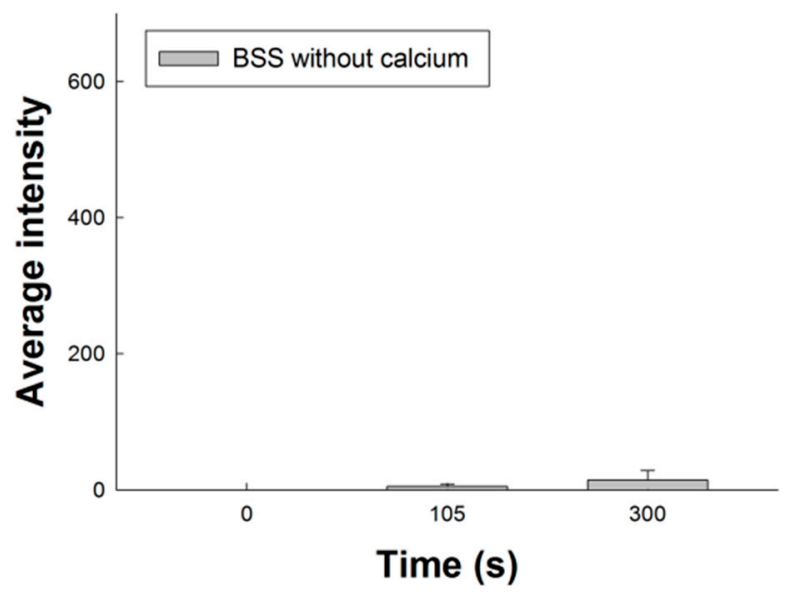

(C)

Figure 5. Effects of SM extracts on the fluorescence intensity of $\mathrm{Ca}^{2+}$ signaling in primary LES cells stained with fluo-4-acetoxymethyl ester and detected by confocal microscopy. $\mathrm{SM}$ extracts were diluted as $0.5 \mu \mathrm{L} / \mathrm{mL}$ in $\mathrm{Ca}^{2+}$-containing or $\mathrm{Ca}^{2+}$-free BSS. The SM extracts were added at the 60th s (A) The three images of upper row show the fluorescence intensity of $\mathrm{Ca}^{2+}$ signaling in primary LES smooth muscle cells increased significantly in the $\mathrm{Ca}^{2+}$-containing BSS after SM treatment. On the contrary, there was no significant change in the $\mathrm{Ca}^{2+}$-free BSS after SM treatment; (B) The mean relative fluorescence intensity $\left(\mathrm{F}-\mathrm{F}_{0}\right.$, where $\mathrm{F}_{0}=$ the first image of the sequence and $\mathrm{F}=$ subsequent images $)$ in smooth muscle cells at the 300th $\mathrm{s}$ in the $\mathrm{Ca}^{2+}$-containing BSS after SM treatment increased significantly; (C) The mean relative fluorescence intensity in smooth muscle cells at the 105 th or 300 th $\mathrm{s}$ in the $\mathrm{Ca}^{2+}$-free BSS after SM treatment did not increase significantly. Scale bar represents $40 \mu \mathrm{m}$. * Significant difference between these two groups at $p<0.05$.

Figure 6A shows primary LES cells treated by $1 \mu \mathrm{M}$ thapsigargin (TG) at the 30th s in calcium-free BSS solution and $0.5 \mu \mathrm{L}$ SM extract stimulation or $\mathrm{Ca}^{2+}$-free BSS solution (control group) added to $1 \mathrm{~mL}$ $\mathrm{Ca}^{2+}$-free BSS at the 10th min. The $\left[\mathrm{Ca}^{2+}\right]_{\mathrm{i}}$ in the SM extract stimulation group was more than in the control group after addition of $2 \mathrm{mM} \mathrm{CaCl}_{2}$ at the 13th $\min (n=3)$. These results indicate SM extracts increase $\left[\mathrm{Ca}^{2+}\right]_{i}$ in primary LES cells by inducing extracellular $\mathrm{Ca}^{2+}$ entry into smooth muscle cells. Figure 6B shows primary LES smooth muscle cells pretreated with only $0.5 \mu \mathrm{L}$ SM extracts, $0.5 \mu \mathrm{L}$ SM extracs with $25 \mu \mathrm{M}$ 2-aminoethoxydiphenyl borate (2APB, a store operated channel blocker), $0.5 \mu \mathrm{L}$ SM extracts with $20 \mu \mathrm{M}$ SKF-96365 (SKF, a store operated channel blocker), $0.5 \mu \mathrm{L}$ SM extracts with $25 \mu \mathrm{M}$ 1,2-bis(2-aminophenoxy)ethane- $N, N, N^{\prime}, N^{\prime}$-tetraacetic acid tetrakis (acetoxymethyl ester) (BAPTA-AM, a chelator of cytosolic $\mathrm{Ca}^{2+}$ ), and $\mathrm{Ca}^{2+}$-containing BSS (control group) to $1 \mathrm{~mL} \mathrm{Ca}^{2+}$-containing BSS and $1 \mu \mathrm{M}$ TG was applied to induce $\mathrm{Ca}^{2+}$ influx at the 30th $\mathrm{s}$ by depleting the endoplasmic reticulum calcium stores. The $\left[\mathrm{Ca}^{2+}\right]_{i}$ in the group of only SM extracts pretreatment was more than the other groups $(n=3)$. These results indicate $\mathrm{Ca}^{2+}$ influx is the main pathway of increased $\left[\mathrm{Ca}^{2+}\right]$ i induced by SM extracts. 


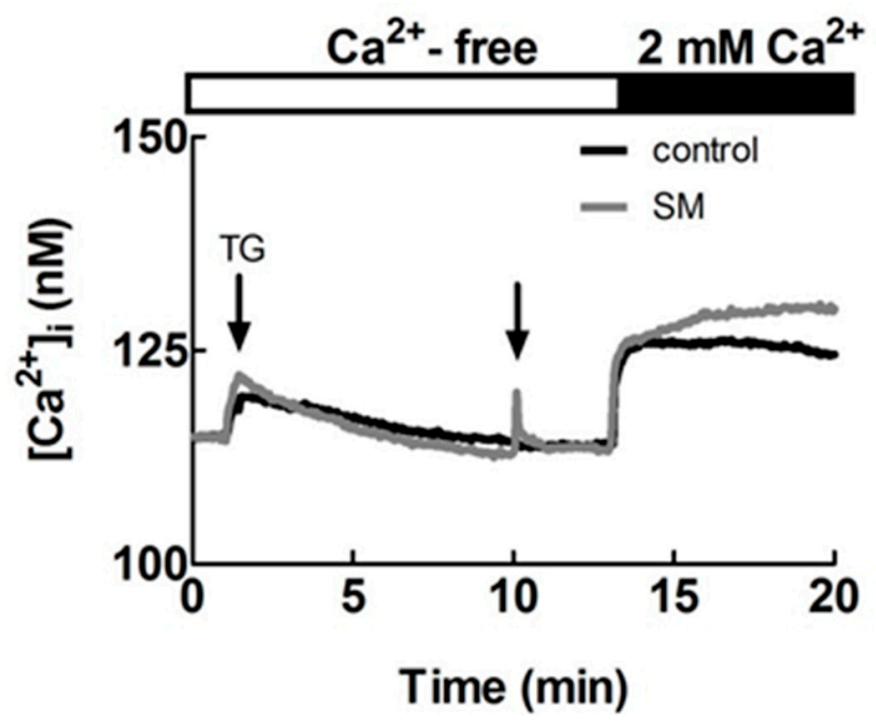

(A)

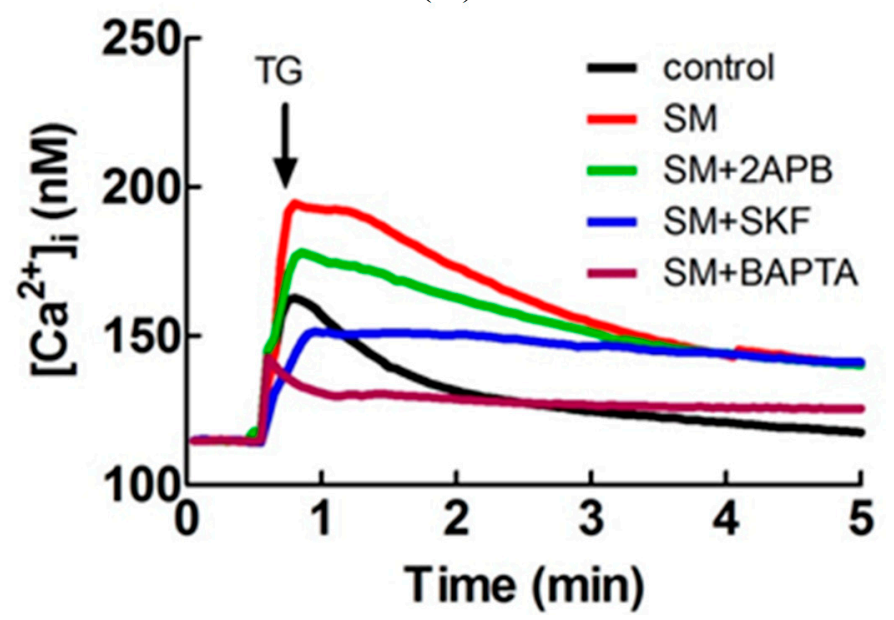

(B)

Figure 6. Effects of SM extracts on cytosolic concentration of free $\mathrm{Ca}^{2+}\left(\left[\mathrm{Ca}^{2+}\right] \mathrm{i}\right)$ in primary LES cells stained with fluo-4 acetoxymethyl ester and detected by the Olympus Cell^R. (A) $1 \mu \mathrm{M}$ thapsigargin (TG) treatment was performed at the 30th s and $0.5 \mu \mathrm{L}$ SM extracts stimulations or $\mathrm{Ca}^{2+}$-free BSS solution (control group) was added to $1 \mathrm{~mL} \mathrm{Ca}^{2+}$-free BSS solution at the 10th $\mathrm{min}$. The $\left[\mathrm{Ca}^{2+}\right]$ in the SM extract stimulation group was more than the control group after addition of $2 \mathrm{mM} \mathrm{CaCl}_{2}$ at the 13th $\min (n=3)$; (B) Primary LES smooth muscle cells were pretreated with $0.5 \mu \mathrm{L}$ SM extracts, $0.5 \mu \mathrm{L}$ SM extract with $20 \mu \mathrm{M}$ 2-aminoethoxydiphenyl borate (2APB), $0.5 \mu \mathrm{L}$ SM extracts with 2-aminoethoxydiphenyl borate (2APB), $0.5 \mu \mathrm{L}$ SM extracts with $20 \mu \mathrm{M}$ SKF-96365 (SKF), $0.5 \mu \mathrm{L}$ SM extracts with $25 \mu \mathrm{M}$ 1,2-bis(2-aminophenoxy)ethane- $N, N, N^{\prime}, N^{\prime}$-tetraacetic acid tetrakis(acetoxymethyl ester) (BAPTA-AM), and $0.5 \mu \mathrm{L} \mathrm{BSS} \mathrm{(control} \mathrm{group)} \mathrm{to} 1 \mathrm{~mL} \mathrm{Ca}^{2+}$-containing BSS solution. $1 \mu \mathrm{M}$ TG was applied to induce $\mathrm{Ca}^{2+}$ influx at the 30 th $\mathrm{s}$ The $\left[\mathrm{Ca}^{2+}\right] \mathrm{i}$ in the group of only $\mathrm{SM}$ extracts pretreatment was more than the other groups $(n=3)$. 


\section{Experimental Section}

\subsection{Materials}

This study was carried out in strict accordance with the recommendations in the Guide for the Care and Use of Laboratory Animals of Council of Agriculture, Executive Yuan, Taiwan. The protocol was approved by the Animal Care and Use Committee at E-Da Hospital (Permit Number: IACUC-103025). All rats were directly sacrificed by $\mathrm{CO}_{2}$ and all efforts were made to minimize suffering. Male Sprague-Dawley rats were obtained from the BioLASCO Taiwan (Taipei, Taiwan). Carbachol, atropine, nifedipine, papain, collagenase II, dispase II and buffer reagents were obtained from Sigma-Aldrich (St. Louis, MO, USA). Fura-2-acetoxymethyl ester (Fura-2 AM) and fluo-4 AM were purchased from Invitrogen (Carlsbad, CA, USA). Tetrodotoxin was purchased from Tocris Cookson Inc. (Avonmouth Bristol, UK). TA was obtained from the National Institute for Control of Biological and Pharmaceutical Products of China (Beijing, China) and its purity was more than $98 \%$ by HPLC analysis.

\subsection{Preparation of SM Extracts}

Dried roots of SM were obtained from Winpower Biotech. Co., Ltd. (Kaohsiung, Taiwan). The authentication of SM roots was done on the basis of standards and methods provided as listed in Zhonghua Bencao [24]. A herbarium sample, coding number ISU-CMPB-0012, was maintained in the School of Chinese Medicine for Post-Baccalaureate, I-Shou University (Kaohsiung, Taiwan) for future reference. The dried roots of SM (100 g) were cut up in about $1 \mathrm{~cm}$ lengths and then ground using a pulverizer. $95 \%$ Ethanol was used to extract the roots of SM three times for $18 \mathrm{~h}$. The ethanol extracts were combined and concentrated to $50 \mathrm{~mL}$ under vacuum. A membrane filter $(0.45 \mu \mathrm{m})$ was used to filter the solutions which were then infused into the HPLC for analysis or used in the study of contraction of LES. In this present study, the extraction yield of TA from SM roots was determined as follows [25]:

$$
\text { Extraction yield }(w / w)=\frac{\text { Mass of tanshinone }(\text { in extracted solution })}{\text { Mass of material }(\text { roots of SM) }} \times 100 \%
$$

\subsection{HPLC Analysis of TA in SM Extracts}

The chromatographic system consisted of a LC-10AT pump, a SIL-10AF autosampler and a SPD-10Avp UV-VIS detector (Shimadzu, Kyoto, Japan). A Purospher ${ }^{\circledR}$ STAR RP-18 endcapped (250 $\mathrm{mm} \times 4.6 \mathrm{~mm}$ i.d., $5 \mu \mathrm{m}$ ) (Merck, Darmstadt, Germany) was applied for the separation and temperature was controlled at $25{ }^{\circ} \mathrm{C}$. The mobile phase was made up of $75 \%$ acetonitrile, $12.5 \%$ methanol and $12.5 \%$ water at volumetric ratios and $\mathrm{pH}$ was titrated to 3.0 with glacial acetic acid. The detection was monitored at $270 \mathrm{~nm}$. The mobile phase was delivered at a rate of $1.0 \mathrm{~mL} / \mathrm{min}$ and the volume of injection loop was $10 \mu \mathrm{L}$. Diazepam was used as the internal standard. The sample calibration curve for TA was linear $(\mathrm{r}=0.9999)$ within the range $0-50 \mathrm{mg} / \mathrm{mL}$. Intra- and inter-day coefficients of variation of the assays were less than $5 \%(n=6)[26]$. 


\subsection{Measurement of Contraction of LES in Rat}

Measurements of contraction of the isolated LES were performed according to the procedure previously described in detail [16,27]. Sprague-Dawley (SD) rats, each weighing 350-400 g, were euthanized with $\mathrm{CO}_{2}$ directly in a sealed plastic bag and confirmed to be dead through observation of discontinuation of respiration and palpation of cessation of heartbeat. The abdomen was opened by surgical scissors and the stomach and lower portion of the esophagus were removed and cut open in the longitudinal direction along the greater curvature. The mucosa was cleared away by surgical forceps. A transverse strip (10 $\mathrm{mm}$ long and $2 \mathrm{~mm}$ wide) was cut from the LES, which was identified as a pink thickened muscle between the stomach and the esophagus. The muscle strips were mounted in 7-mL organ baths containing Krebs-Henseleit solution $(118 \mathrm{mM} \mathrm{NaCl}, 25 \mathrm{mM} \mathrm{NaHCO}, 4.7 \mathrm{mM} \mathrm{KCl}$, $14 \mathrm{mM}$ glucose, $1.2 \mathrm{mM} \mathrm{NaH}_{2} \mathrm{PO}_{4}$, and $1.8 \mathrm{mM} \mathrm{CaCl}_{2}$ ) at $37{ }^{\circ} \mathrm{C}$ and being oxygenated with $95 \% \mathrm{O}_{2}+$ $5 \% \mathrm{CO}_{2}$. The muscle strips were linked by surgical silk sutures to isometric transducers (FT.03; Grass Technologies, West Warwick, RI, USA), which were attached to an amplifier (Gould Instrument Systems, Valley View, OH, USA) and a computer recording system (BIOPAC Systems, Santa Barbara, CA, USA). The resting tension of the muscle strips was adjusted to $1.0 \mathrm{~g}$. After a 30 -min equilibration period, carbachol was added into organ bath to check the activity of muscle strip and then washed out. Another equilibration period was performed. SM extracts $(40 \mu \mathrm{L}, 100 \mu \mathrm{L}, 180 \mu \mathrm{L}$, and $280 \mu \mathrm{L})$ were added in a cumulative-dose administration into $7-\mathrm{mL}$ organ baths. The muscle strips of LES were removed from the bath, blotted dry, and weighed (tissue wet weight) at the end of each experiment. The AUC (g/g tissue/s) was calculated.

\subsection{Effect of Tetrodotoxin, Atropine, Nifedipine and $\mathrm{Ca}^{2+}$-Free Krebs-Henseleit Solution with EGTA on SM Extract-Induced Contraction of LES in Rat}

To investigate the mechanism of SM extract-induced contraction of LES, the isolated LES was pretreated with the $\mathrm{Na}^{+}$channel blocker TTX $\left(10^{-6} \mathrm{M}\right)$ and followed 15 min later by addition of SM extract to the organ bath [28,29]. The isolated LES was also pre-treated with the non-selective muscarinic receptor antagonist atropine $\left(10^{-6} \mathrm{M}\right)$ followed 6 min later by addition of SM extract. Isolated LES was also pretreated with the L-type $\mathrm{Ca}^{2+}$ channel blocker nifedipine $\left(10^{-6} \mathrm{M}\right)$ followed 20 min later by addition of SM extract. $\mathrm{Ca}^{2+}$-free Krebs-Henseleit solution had a similar composition of Krebs-Henseleit solution except for the $\mathrm{Ca}^{2+}$ and it contained $0.5 \mathrm{mM}$ EGTA. The solution in organ bath was replaced by $\mathrm{Ca}^{2+}$-free Krebs-Henseleit solution with EGTA and SM extracts were added into organ baths $[16,30]$.

\subsection{Enzymatic Isolation of Primary LES Smooth Muscle Cells}

Single smooth muscle cells from LES of Male SD rats were freshly isolated using enzymatic digestion. Briefly, muscular strips of the LES were cut in small pieces and incubated in a $30 \mu \mathrm{L} / \mathrm{mL}$ papain solution for 10 min, washed with Hank's Balanced Salt Solution (HBSS) and incubated for an additional $15 \mathrm{~min}$ with a mixture of collagenase type II $4 \mathrm{mg} / \mathrm{mL}$ and dispase II $4.5 \mathrm{mg} / \mathrm{mL}$ at $37{ }^{\circ} \mathrm{C}$, then washed with HBSS again. After stopping the enzyme reaction with Dulbecco's Modified Eagle medium (DMEM), the cells were cultured in dishes [31]. 


\section{7. $\left[\mathrm{Ca}^{2+}\right]_{i}$ Measurements}

Fura-2 AM was applied as a $\mathrm{Ca}^{2+}$ probe to detect the $\left[\mathrm{Ca}^{2+}\right]_{\mathrm{i}}$ and measurement of $\left[\mathrm{Ca}^{2+}\right]_{\mathrm{i}}$ was performed according to the procedure previously described in detail [32,33]. 10 $0^{-6} \mathrm{M}$ AM form of fura-2 was added to trypsinized cells $\left(10^{6} / \mathrm{mL}\right)$ at $25^{\circ} \mathrm{C}$ for $30 \mathrm{~min}$ in DMEM. Fura-2 fluorescence measurements were performed in a water-jacketed cuvette $\left(25^{\circ} \mathrm{C}\right)$ with continuous stirring; the cuvette contained $1 \mathrm{~mL}$ of medium and 0.5 million cells. A Shimadzu RF-5301PC spectrofluorophotometer (Shimadzu, Kyoto, Japan) was used to monitor fluorescence by recording excitation signals at $340 \mathrm{~nm}$ and $380 \mathrm{~nm}$ of light and emission signal at $510 \mathrm{~nm}$ of light at $2 \mathrm{~s}$ intervals. $1 \%$ Triton X100 and $20 \mathrm{mM}$ EGTA were sequentially added at the end of each experiment to determine maximum and minimum fluorescence values. $\mathrm{Ca}^{2+}$-containing medium is composed of $5 \mathrm{mM} \mathrm{KCl}, 140 \mathrm{mM} \mathrm{NaCl}$, $2 \mathrm{mM} \mathrm{CaCl}_{2}, 1 \mathrm{mM} \mathrm{MgCl}$, $10 \mathrm{mM}$ HEPES, and $5 \mathrm{mM}$ glucose; the $\mathrm{pH}$ was adjusted to 7.4 with $1 \mathrm{~N}$ $\mathrm{NaOH}$. $\mathrm{Ca}^{2+}$-free medium had a similar composition except for the absence of $\mathrm{Ca}^{2+}$ and it contained $1 \mathrm{mM}$ EGTA. The extracts of $\mathrm{SM}(0.5 \mu \mathrm{L}$ or $0.1 \mu \mathrm{L})$ were added into $1 \mathrm{~mL} \mathrm{Ca}^{2+}$-containing or $\mathrm{Ca}^{2+}$-free media at the 60 th $\mathrm{s}$ to measure the $\mathrm{Ca}^{2+}$ levels in primary LES cells.

\subsection{Confocal Microscope Fluorescent Images}

Fluo-4 AM was applied as $\mathrm{Ca}^{2+}$-sensitive fluorescent indicator and the fluorescence intensity of intracellular $\left[\mathrm{Ca}^{2+}\right]$ in primary LES smooth muscle cells were detected using a confocal microscope (Olympus FV 1000, Tokyo, Japan). Briefly, 105/mL primary LES smooth muscle cells were seeded onto the glass coverslips in six well plastic plates to grow. Two days later, culture medium was removed and cells were washed with BSS and incubated with $1 \mu \mathrm{M}$ fluo-4 AM solution for 20 min at $37^{\circ} \mathrm{C}$. Fluo- 4 AM solution was removed and cells was washed out again with BSS. The coverslip was nipped on special holder and the confocal microscope was used to detect calcium imaging at $3 \mathrm{~s}$ intervals for 6 min. The $0.5 \mu \mathrm{L}$ extracts of SM were sequentially added into $1 \mathrm{~mL} \mathrm{Ca}^{2+}$-containing or $\mathrm{Ca}^{2+}$-free $\mathrm{BSS}$ on the holder at 1st min. BSS consisted of $5.4 \mathrm{mM} \mathrm{KCl}, 5.5 \mathrm{mM}$ D-glucose, $1 \mathrm{mM} \mathrm{MgSO} 4,130 \mathrm{mM} \mathrm{NaCl}$, $20 \mathrm{mM}$ HEPES, $2 \mathrm{mM} \mathrm{CaCl}_{2}$ and $\mathrm{pH}$ was adjusted to 7.4. $\mathrm{Ca}^{2+}$-free BSS had a similar composition except $\mathrm{Ca}^{2+}$. Similarly, Cell^R IX81 fluorescence microscope (Olympus, Hamburg, Germany) with fluo-4 AM staining was also applied to detect the intracellular calcium responses to stimulation, such as by $\mathrm{CaCl}_{2}$ or TG. Calcium concentration was calculated using the following formula: $\left[\mathrm{Ca}^{2+}\right]_{\mathrm{i}}=$ $\mathrm{K}_{\mathrm{D}} \times\left[\left(\mathrm{F}-\mathrm{F}_{\min }\right) /\left(\mathrm{F}_{\max }-\mathrm{F}\right)\right]$. Plotting the fluorescence intensity versus $\left[\mathrm{Ca}^{2+}\right]$ i yielded the calibration curve with the formula of: $\left[\mathrm{Ca}^{2+}\right]_{i}=\mathrm{K}_{\mathrm{D}} \times\left[\left(\mathrm{F}-\mathrm{F}_{\min }\right) /\left(\mathrm{F}_{\max }-\mathrm{F}\right)\right]$, where $\mathrm{K}_{\mathrm{D}}=150.5 \mathrm{nM}$, $\mathrm{F}=$ Fluo-4 intensity, $F_{\max }=640$, and $F_{\min }=21.7$ for Fluo-4 [34,35].

\subsection{Data Analysis}

These data were expressed as means \pm standard deviation, and statistical analysis of the results was performed by using Student $t$ test. In all cases, differences were considered significant when $p<0.05$.

\section{Conclusions}

The present study demonstrates that SM causes tonic contraction of LES. The SM-induced contraction may not relate to neuronal conduction, muscarinic receptors, and L-type voltage-dependent 
calcium channels. This study provides the evidence that the SM-induced contraction of LES is mainly associated with extracellular $\mathrm{Ca}^{2+}$ influx, especially through store operated calcium channels. Hence, SM has the potential to treat the patients with proton pump inhibitor refractory GERD.

\section{Acknowledgments}

This study was supported by intramural funding, provided by the E-Da hospital (EDAHP102021, EDAHP103008, EDAHP103036).

\section{Author Contributions}

C.-C.T. and L.-C.C. designed research and supervised S.-C.H. and T.-R.T.; C.-C.T., W.-L.H. and performed most of the experiments, whereas C.-C.T., S.-C.H., S.-L.T., and Y.-T.S. analyzed the data. C.-C.T. and L.-C.C. wrote the paper. C.-W.L. performed primary culture of LES. All authors read and approved the final manuscript.

\section{Conflicts of Interest}

The authors declare no conflict of interest.

\section{References}

1. Boeckxstaens, G.E. The lower oesophageal sphincter. Neurogastroenterol. Motil. 2005, 17, 13-21.

2. Sifrim, D.; Zerbib, F. Diagnosis and management of patients with reflux symptoms refractory to proton pump inhibitors. Gut 2012, 61, 1340-1354.

3. Bredenoord, A.J.; Pandolfino, J.E.; Smout, A.J. Gastro-oesophageal reflux disease. Lancet 2013, 381, 1933-1942.

4. Yasawy, M.I.; Randhawa, M.A. GERD is becoming a challenge for the medical profession: Is there any remedy? Hepatogastroenterology 2014, 61, 1623-1626.

5. Pharmacopoeia Commission of People's Republic of China. Pharmacopoeia of the People's Republic of China; Chemical Industry Press: Beijing, China, 2010; p. 71.

6. Wang, X.; Morris-Natschke, S.L.; Lee, K.H. New developments in the chemistry and biology of the bioactive constituents of Tanshen. Med. Res. Rev. 2007, 27, 133-148.

7. Li, M.H.; Chen, J.M.; Peng, Y.; Wu, Q.; Xiao, P.G. Investigation of Danshen and related medicinal plants in China. J. Ethnopharmacol. 2008, 120, 419-426.

8. Cao, C.M.; Xia, Q.; Zhang, X.; Xu, W.H.; Jiang, H.D.; Chen, J.Z. Salvia miltiorrhiza attenuates the changes in contraction and intracellular calcium induced by anoxia and reoxygenation in rat cardiomyocytes. Life Sci. 2003, 72, 2451-2463.

9. Lam, F.F.; Deng, S.Y.; Ng, E.S.; Yeung, J.H.; Kwan, Y.W.; Lau, C.B.; Koon, J.C.; Zhou, L.; Zuo, Z.; Leung, P.C.; et al. Mechanisms of the relaxant effect of a Danshen and Gegen formulation on rat isolated cerebral basilar artery. J. Ethnopharmacol. 2010, 132, 186-192.

10. Chan, K.; Chui, S.H.; Wong, D.Y.; Ha, W.Y.; Chan, C.L.; Wong, R.N. Protective effects of Danshensu from the aqueous extract of Salvia miltiorrhiza (Danshen) against homocysteine-induced endothelial dysfunction. Life Sci. 2004, 75, 3157-3171. 
11. Guo, Y.; Li, Y.; Xue, L.; Severino, R.P.; Gao, S.; Niu, J.; Qin, L.P.; Zhang, D.; Brömme, D. Salvia miltiorrhiza: An ancient Chinese herbal medicine as a source for anti-osteoporotic drugs. J. Ethnopharmacol. 2014, 155, 1401-1416.

12. Chen, X.; Guo, J.; Bao, J.; Lu, J.; Wang, Y. The anticancer properties of Salvia miltiorrhiza Bunge (Danshen): A systematic review. Med. Res. Rev. 2014, 34, 768-794.

13. Zhang, Z.Y.; Chen, X.P.; Lu, Q.P. Effect of Salvia miltiorrhiza pretreatment on the CCK and VIP expression in hepatic ischemia-reperfusion-induced digestive tract congestion. Front. Med. China 2010, 4, 317-322.

14. Wen, X.D.; Wang, C.Z.; Yu, C.; Zhang, Z.; Calway, T.; Wang, Y.; Li, P.; Yuan, C.S. Salvia miltiorrhiza (Danshen) significantly ameliorates colon inflammation in dextran sulfate sodium induced colitis. Am. J. Chin. Med. 2013, 41, 1097-1108.

15. Xiping, Z.; Yan, P.; Xinmei, H.; Guanghua F.; Meili, M.; Jie, N.; Fangjie, Z. Effects of dexamethasone and Salvia miltiorrhizae on the small intestine and immune organs of rats with severe acute pancreatitis. Inflammation 2010, 33, 259-266.

16. Tsai, C.C.; Huang, S.C.; Liu, J.K.; Wang, H.C.; Tsai, T.R.; Tsai, P.J.; Liu, C.W.; Chang, L.C. Salvia miltiorrhiza causes tonic contraction in rat ileum through $\mathrm{Ca}^{2+}$-calmodulin pathway. J. Ethnopharmacol. 2012, 142, 694-699.

17. Farré, R.; Sifrim, D. Regulation of basal tone, relaxation and contraction of the lower oesophageal sphincter. Relevance to drug discovery for oesophageal disorders. Br. J. Pharmacol. 2008, 153, $858-869$.

18. Muinuddin, A.; Neshatian, L.; Gaisano, H.Y.; Diamant, N.E. Calcium source diversity in feline lower esophageal sphincter circular and sling muscle. Am. J. Physiol. Gastrointest. Liver Physiol. 2004, 286, 271-277.

19. Biancani, P.; Sohn, U.D.; Rich, H.G.; Harnett, K.M.; Behar, J. Signal transduction pathways in esophageal and lower esophageal sphincter circular muscle. Am. J. Med. 1997, 103, 23S-28S.

20. Hornby, P.J.; Abrahams, T.P. Central control of lower esophageal sphincter relaxation. Am. J. Med. 2000, 108, 90-98.

21. Wang, J.; Laurier, L.G.; Sims, S.M.; Preiksaitis, H.G. Enhanced capacitative calcium entry and TRPC channel gene expression in human LES smooth muscle. Am. J. Physiol. Gastrointest. Liver Physiol. 2003, 284, doi:10.1152/ajpgi.00227.2002.

22. Sims, S.M.; Jiao, Y.; Preiksaitis, H.G. Regulation of intracellular calcium in human esophageal smooth muscle. Am. J. Physiol. 1997, 273, 1679-1689.

23. Sanders, K.M. Signal transduction in smooth muscle: Mechanisms of calcium handling in smooth muscles. J. Appl. Physiol. 2001, 91, 1438-1449.

24. Zhonghua Bencao Committee of State Traditional Chinese Medicine Administration. Zhonghua Bencao; Shanghai Scientific and Technical Press: Shanghai, China, 1999; pp. 169-186.

25. Pan, X.; Niu, G.; Liu, H. Microwave-assisted extraction of tanshinones from Salvia miltiorrhiza bunge with analysis by high-performance liquid chromatography. J. Chromatogr. A 2001, 922, 371-375.

26. Chang, L.C.; Wu, C.L.; Liu, C.W.; Chuo, W.H.; Li, P.C.; Tsai, T.R. Preparation, characterization and cytotoxicity evaluation of tanshinone IIA nanoemulsions. J. Biomed. Nanotechnol. 2011, 7, $558-567$. 
27. Huang, S.C. Dendroaspis natriuretic peptide is the most potent natriuretic peptide to cause relaxation of lower esophageal sphincter. Regul. Pept. 2011, 167, 246-249.

28. Nagao, M.; Linden, D.R.; Duenes, J.A.; Sarr, M.G. Mechanisms of action of the gasotransmitter hydrogen sulfide in modulating contractile activity of longitudinal muscle of rat ileum. J. Gastrointest. Surg. 2011, 15, 12-22.

29. Chang, B.S.; Chang, J.C.; Wang, Y.S.; Huang, S.C. Cysteinyl leucotriene receptor type 1 mediates contraction in human and guinea-pig oesophagus. Neurogastroenterol. Motil. 2008, 20, 1140-1146.

30. Park, S.Y.; Je, H.D.; Shim, J.H.; Sohn, U.D. Characteristics of spontaneous contraction in the circular smooth muscles of cat ileum. Arch. Pharm. Res. 2010, 33, 159-165.

31. Bautista-Cruz, F.; Paterson, W.G. Evidence for altered circular smooth muscle cell function in lower esophageal sphincter of W/Wv mutant mice. Am. J. Physiol. Gastrointest. Liver Physiol. 2011, 301, doi:10.1152/ajpgi.00020.2011.

32. Grynkiewicz, G.; Poenie, M.; Tsien, R.Y. A new generation of $\mathrm{Ca}^{2+}$ indicators with greatly improved fluorescence properties. J. Biol. Chem. 1985, 260, 3440-3450.

33. Ohta, T.; Ito, S.; Nakazato, Y. Chloride currents activated by caffeine in rat intestinal smooth muscle cells. J. Physiol. 1993, 465, 149-162.

34. Zohar, O.; Ikeda, M.; Shinagawa, H.; Inoue, H.; Nakamura, H.; Elbaum, D.; Alkon, D.L.; Yoshioka, T. Thermal imaging of receptor-activated heat production in single cells. Biophys. J. 1998, 74, 82-89.

35. Florea, A.M.; Splettstoesser, F.; Büsselberg, D. Arsenic trioxide (As2O3) induced calcium signals and cytotoxicity in two human cell lines: SY-5Y neuroblastoma and 293 embryonic kidney (HEK). Toxicol. Appl. Pharmacol. 2007, 220, 292-301.

Sample Availability: Samples in the present paper are not available from the authors.

(C) 2015 by the authors; licensee MDPI, Basel, Switzerland. This article is an open access article distributed under the terms and conditions of the Creative Commons Attribution license (http://creativecommons.org/licenses/by/4.0/). 